Chemical Geology, 13 (1974) 217-232

c Elsevier Scientific Publishing Company, Amsterdam - Printed in The Netherlands

\title{
IDENTIFICATION OF SEDIMENTARY CYCLES THROUGH FOURIER ANAL YSIS OF GEOCHEMICAL DATA
}

\author{
COLIN E. DUNN
}

Department of Mineral Resources, Saskatchewan Government, Regina, Sask. (Canada) (Accepted for publication April 5, 1974)

\section{ABSTRACT}

Dunn, C.E., 1974. Identification of sedimentary cycles through Fourier analysis of geochemical data. Chem. Geol., 13: 217-232.

Trace elements are sensitive to slight shifts in the chemical equilibrium of a body of water, and as a result they can be expected to reflect cyclical events in the earth's history. Geochemical data from a section of Upper Jurassic (Kimmeridgian) bituminous sediments in Great Britain, $20 \mathrm{~m}$ thick, have been examined by single Fourier series analysis, thereby permitting an objective assessment of sedimentary cycles. Subjectivity only enters into the final interpretative stage.

Assumptions made as to the rate of deposition of these sediments have indicated several superimposed periodicities with respective durations of (?) $200,000,100,000,40,000$, 14,000 , and 11,000 years.

Comparison is made with long-term cyclic durations estimated by other workers. Several of these periods are coincident with the duration of astronomical phenomena which could cause climatic fluctuations.

\section{INTRODUCTION}

Changes in physical environment on the earth's surface induce changes in the chemical equilibrium of a body of water and its associated sedimentary products. Even small changes in average rainfall, temperature, or rate of evaporation modify weathering processes and cause equilibrium shifts which result in the accumulation and association of differing amounts of major and trace elements. If such climatic changes are periodic, the chemical composition of the sediments will reflect the fluctuating equilibrium of the depositional environment.

Evidence of major changes in environment are clearly preserved in the composition of sediments, particularly those deposited in shallow water close to land. Notable examples are the Carboniferous cyclothems of Britain (Hudson, 1924; Johnson, 1959, amongst many others), and the Kansas cyclothems of similar age (Moore, 1949, 1959). Fine-grained marine sediments deposited far from the land surface tend to show much more subtle changes resulting from either modification of the geometry of the sedimentary basin, or from climatic variations, or perhaps from a combination of the two. Con- 
sequently, sedimentary oscillations may not be easily recognized and an objective assessment is clearly desirable. Mathematical analysis of geochemical data can assist in achieving this end.

A detailed geochemical examination was made of a sequence of highly bituminous Kimmeridgian sediments, which forms part of the wheatleyensis and hudlestoni Zones (nomenclature of Cope, 1967) of the coastal cliffs of Dorset, England. Fig.1 illustrates the section studied, which will be referred to as the Blackstone sequence, and the main lithological units into which it has traditionally been divided (Blake, 1875; Arkell, 1933; Downie, 1955). The sediments are all very fine-grained and have an extremely high organic content (over $40 \%$ organic carbon in places) and, for the most part, contacts between lithologies are gradational. Variations in lithology are largely attributable to fluctuations in the relative amounts of organic matter and/or carbonate. The organic component takes the form of kerogen, whilst both dolomite and calcite constitute the carbonates.

Whereas the mineralogy of the sequence is quite simple (organic matter, dolomite, calcite, illite, kaolinite, extremely fine-grained quartz, pyrite and rarely siderite); the trace-element geochemistry varies appreciably (Table I). Statistical analysis of the data has shown $\mathrm{Mo}, \mathrm{P}$, and some of the $\mathrm{Cu}$ and $\mathrm{Ni}$, to be associated with the organic fraction. Most of the other elements, including the remainder of the $\mathrm{Cu}$ and $\mathrm{Ni}$, are structurally incorporated in, or adsorbed on, the clay minerals. Mn is mainly associated with the carbonate fraction. Lithological variation indicates no apparent cyclicity over this inter$\mathrm{val}$, and no clear cycles emerge from the geochemical data.

\section{ANALYTICAL METHODS}

\section{Geochemical}

Sediment samples were each approximately $200 \mathrm{~g}$ of unweathered material and were taken at $25-\mathrm{cm}$ vertical intervals throughout the sequence. All analyses were semi-quantitative. Concentrations of trace elements were established by optical emission spectrography, using a Hilger and Watts large quartz/glass spectrograph. The analytical technique employed was a modification of that described by Kvalheim (1947), using powdered carbon and strontium carbonate as buffers, and palladium as an internal standard. The precision obtained is quoted at the $95 \%$ confidence level after each element: $\mathrm{Cu}( \pm 1.8 .8 \%)$, $\mathrm{Rb}( \pm 19.3 \%), \mathrm{Cr}( \pm 19.7 \%), \mathrm{Ga}( \pm 22.1 \%), \mathrm{Mn}( \pm 24.8 \%), \mathrm{Mo}( \pm 29.1 \%)$, $\mathrm{V}( \pm 33.6 \%)$, Sc $( \pm 34.1 \%), \mathrm{Ni}( \pm 36 \%)$, Cs $( \pm 38.3 \%), \mathrm{Zr}( \pm 39.1 \%), \mathrm{Li}( \pm 42.5 \%)$. Phosphorus $( \pm 10.8 \%)$ was determined by a colorimetric phosphomolybdovanadic acid method (Stanton, 1966). Broad estimates of the organic matter and carbon dioxide contents were made by ignition of the sediment powders and, where concentrations were more than a few percent, precision was appreciably better than for the spectro-chemical work.

Accuracy was checked by analyzing United States Geological Survey stan- 


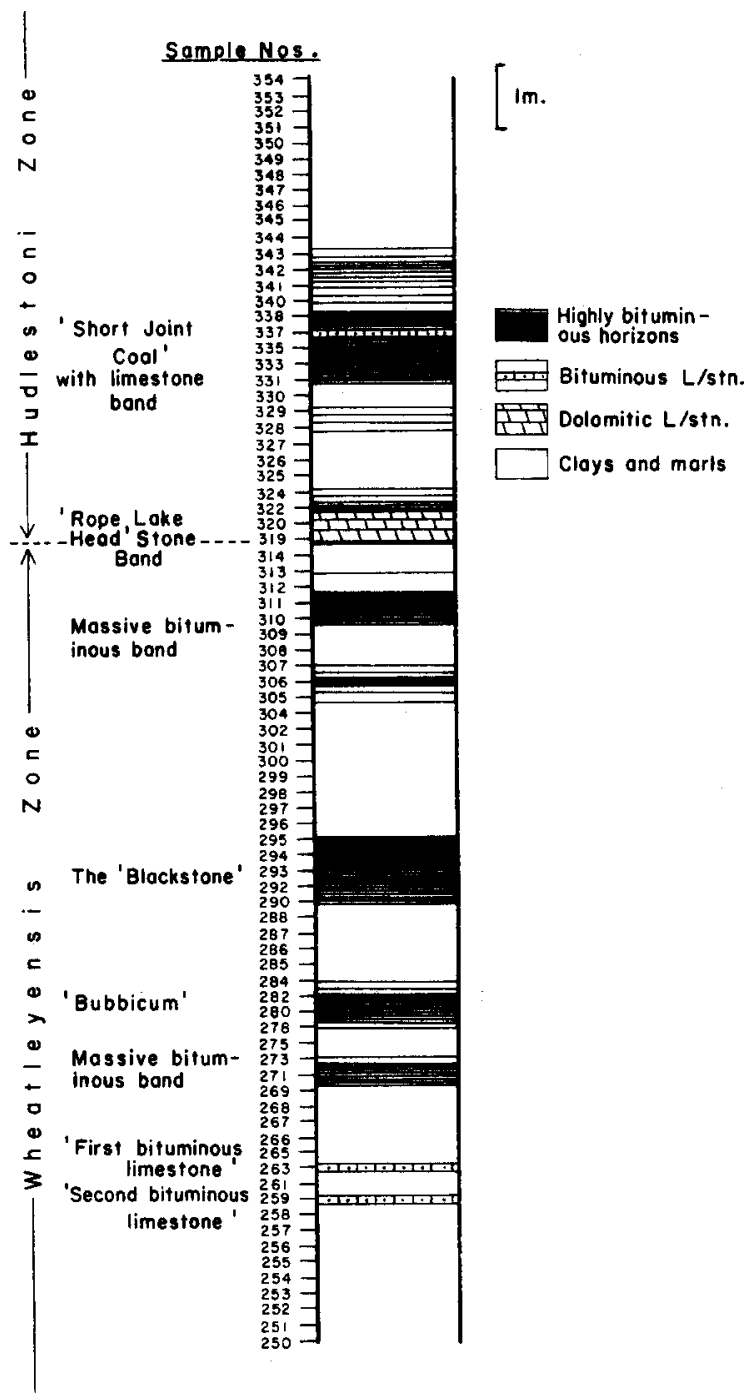

Fig.1. Blackstone sequence (Kimmeridgian) at Clavell's Hard, approximately $1 \mathrm{~km}$ east of Kimmeridge Bay, Dorset, England. Section illustrates the sampling points and the main lithologic divisions.

dard rocks G2, GSP-1, AGV-1, and BCR-1. All analyses lay within the ranges quoted in the literature (Flanagan, 1969) with the exception of $\mathrm{Mn}$ and $\mathrm{Zr}$, for which values obtained in this study appear to be rather high. Full details of the analytical methods with precision, accuracy, wavelengths used and detection limits are given in Dunn, 1972 (unpublished thesis). 


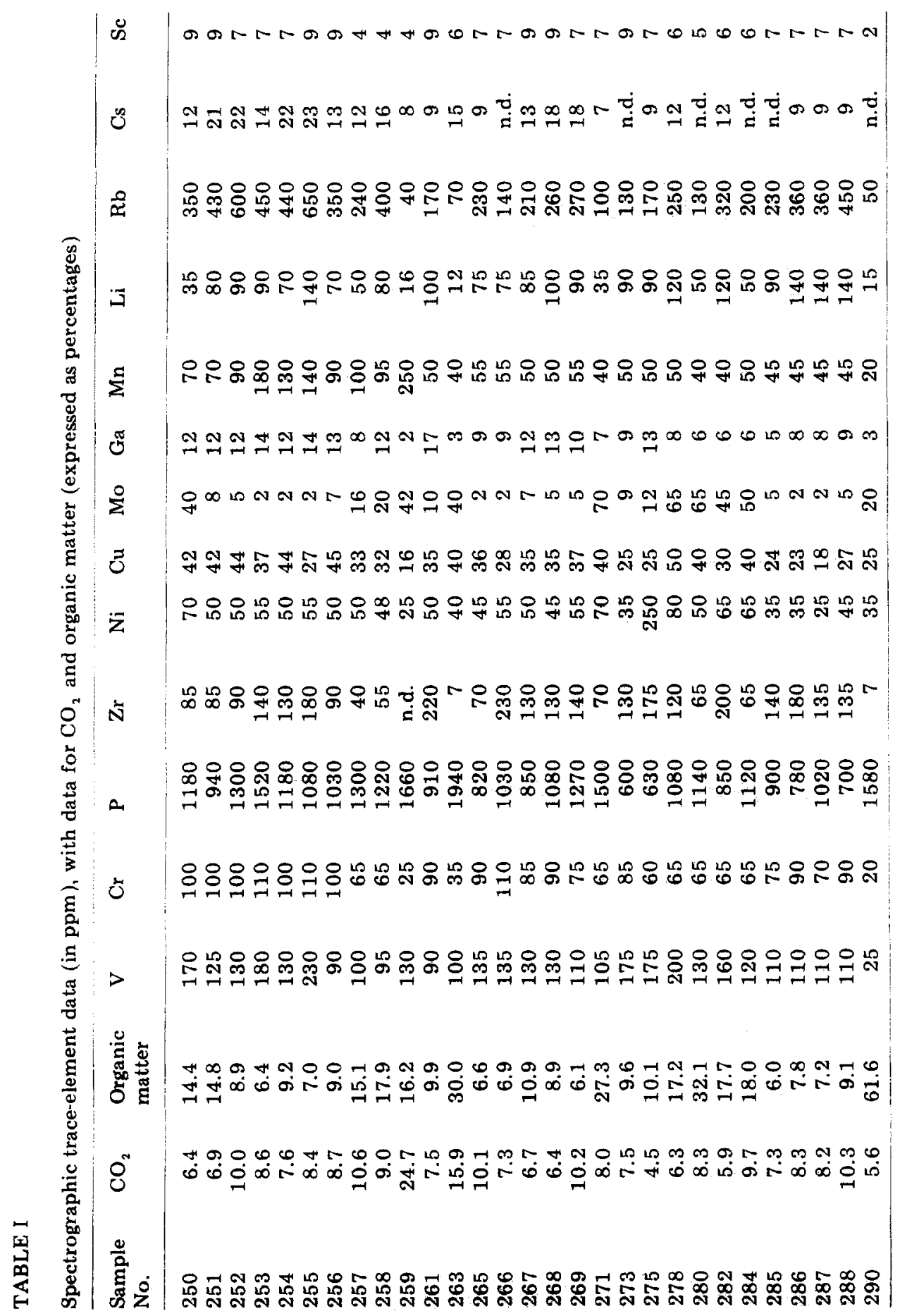




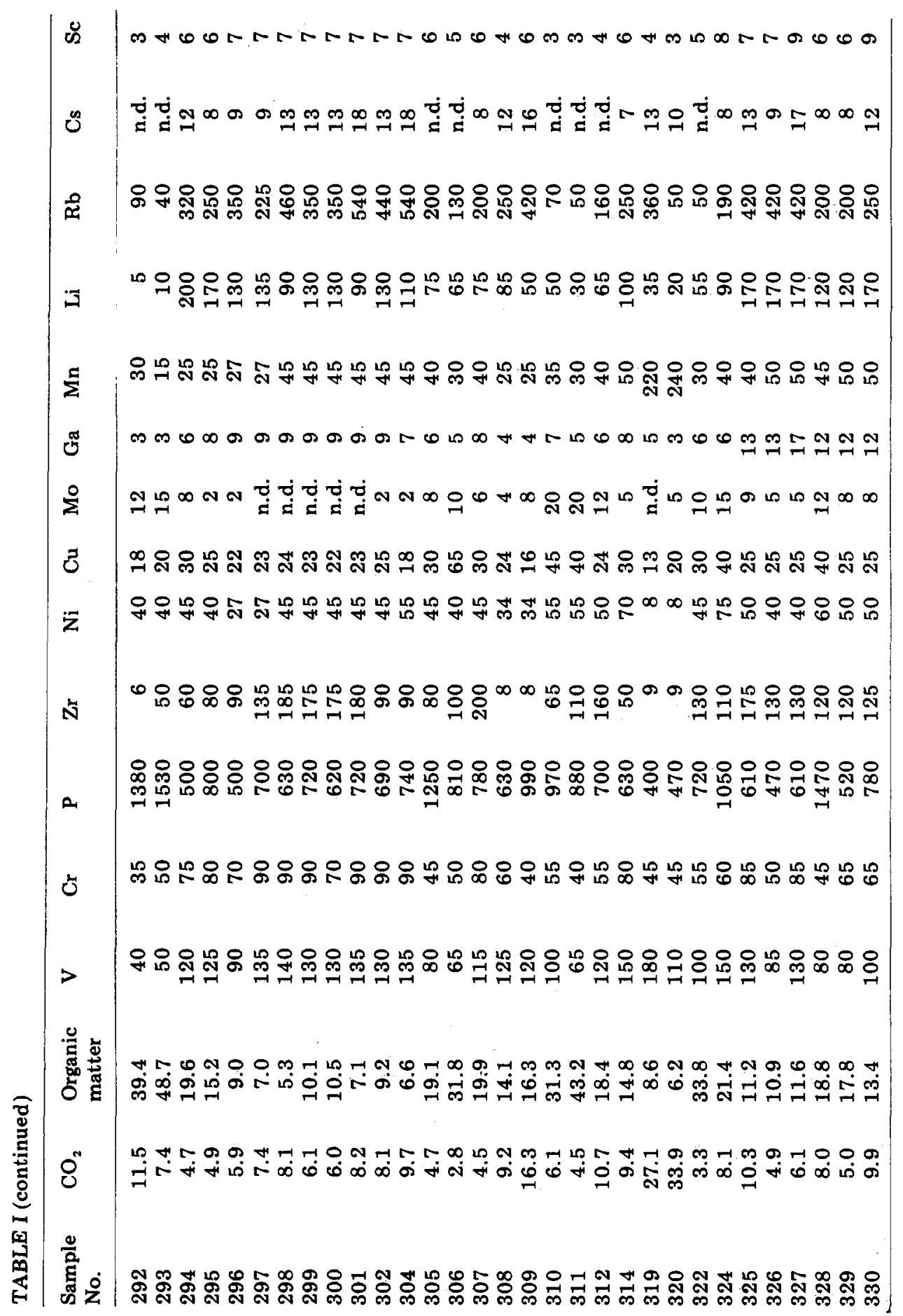




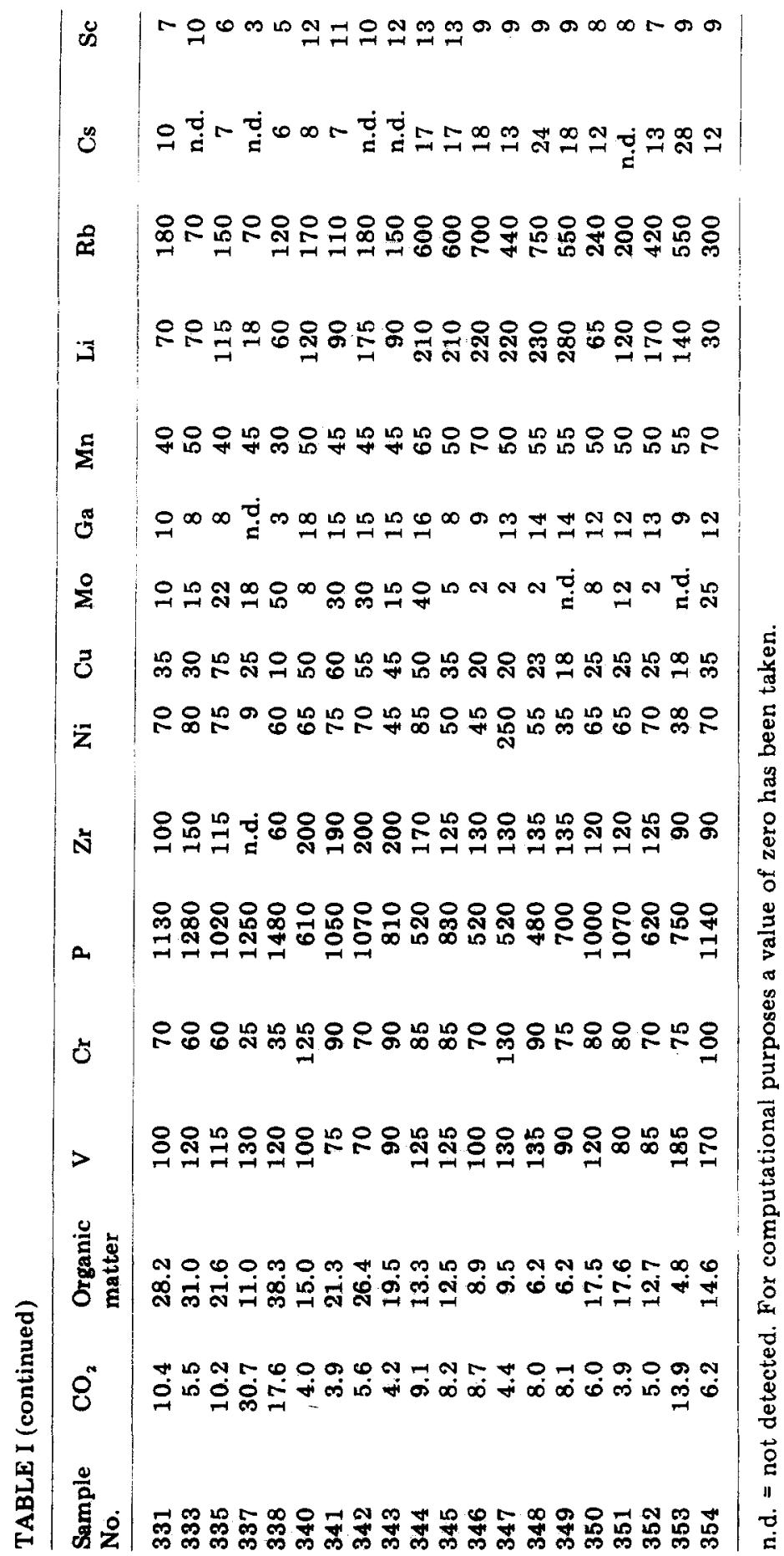




\section{Mathematical technique - single Fourier series analysis}

Fourier series are infinite series comprising sine and cosine terms which are used for harmonic analysis of data. They permit quantification of the extent to which variations in a sequence can be expressed by an oscillatory function. A complex curve may be broken down by single Fourier series analysis into a number of simple harmonics, and examination of the amplitudes of the harmonic waves permits the relative importance of the different wave lengths (i.e., periodicities) to be established. Therefore, a large wave amplitude indicates that much of the data variation may be attributed to the periodicity of that wave. Random oscillations appear as background "noise", above which the other terms rise as peaks. In effect, therefore, single Fourier series analysis is used to unravel a complex data curve into its simple components, thereby isolating superimposed cycles. With respect to geochemical data it may be possible to delineate several climatic periodicities, several tectonic pulses of different duration, or a combination of climatic and tectonic cycles. At this interpretative stage in the analysis one must finally resort to a subjective opinion.

For detailed treatment of the mathematics of Fourier analysis reference should be made to such texts as Lanczos $(1957,1966)$ and Wylie $(1960)$. Excellent summary accounts with applications to some geological problems have been given by Anderson and Koopmans (1963), Preston and Henderson (1964), Preston and Harbaugh (1965), and Harbaugh and Merriam (1968). The computer program used for this study was checked by reconstituting input data, and by running trial data from Preston and Harbaugh (1965).

\section{PRELIMINARY CONSIDERATIONS}

(1) The following interpretation of the Fourier spectra is the most simplistic possible. It lacks sophisticated statistical analysis and therefore the interpretation becomes somewhat subjective. The facts are, however, clearly illustrated in Fig.2, and whereas any conclusions drawn from just one periodogram would be highly questionable (even with a comprehensive statistical analysis), it is felt that the consistent presence of particular harmonics in many spectra lends sufficient weight to validate the conclusions drawn. Although a greater degree of objectivity is obtained by mathematical spectral analysis, it does not provide a conclusive answer - particularly when considering the non-deterministic nature of the data involved in this study (see below). Miller and Kahn (1962, p.250) warn that time series analysis must be treated with great caution, and that in the interpretation of the data the "intuitive grasp of the subject by the investigator should be the final arbitrator".

Recent advances in spectral analysis are comprehensively covered in the following literature: Hannan (1960), Jenkins and Priestley (1957), Granger and Hatanaka (1964), Jenkins and Watts (1968), Otnes and Enochson (1972). 
(2) A greater degree of objectivity can be obtained by analyzing geochemical data from several thousand samples. Jenkins and Watts (1968) stress this from a theoretical standpoint.

(3) Only completely random data will show no variation in harmonic values. Fourier series analysis will pick out periodicities from any other set of data. Small variations in harmonic amplitudes indicate very weak periodicities, hence they are unlikely to have much physical significance and may be wholly attributable to analytical errors.

(4) Because of the oscillatory nature of the Fourier series, only regular periodicities will be brought out strongly whilst irregular periodicities will be smeared as background "noise". Natural sequences of sediments may show irregular periodicities yet still be considered "cyclic" in a geological sense. It is possible, therefore, that quite important lithological cycles of irregular thickness might not show up clearly from a Fourier analysis. This is particularly true where a sedimentary sequence has not been deposited at a fairly constant rate, or where there has been periodic erosion leaving incomplete cycles. Consequently, the technique is only applicable to a continuous sequence where a fairly constant rate of deposition may be assumed, since the "time" variable of the Fourier series is taken as a regular sample interval. If there is good evidence for taking an irregular sample interval as the time element then some meaningful results may emerge, but this is introducing subjective preassessment and some other technique (perhaps Markov Chain) is preferable.

(5) All harmonic terms in a Fourier analysis have period lengths that are simple fractions of the length of the fundamental sampling interval (in this case $20 \mathrm{~m}$ ), hence the low harmonic degree numbers have period lengths which are directly dependent on this arbitrary fundamental sample interval. A peak at a first or second harmonic could, therefore, be a "leakage" (Otnes and Enochson, 1972, p.200) from anywhere between the two harmonics, and thus the validity of interpreting the low harmonic numbers is doubtful.

(6) Time estimations (presented in the next section) for each cyclic period are based on the following assumptions. The estimated duration of the Kimmeridgian Stage is $5 \mathrm{~m} . \mathrm{y}$. (Harland et al., 1964). For the $500 \mathrm{~m}$ thick sequence of sediments in Dorset this gives an average period of about 10,000 years for the deposition of $1 \mathrm{~m}$ of sediment. Since the Kimmeridgian sediments of Dorset are extremely fine-grained throughout all but the very uppermost part of the sequence, this may be a reasonable extrapolation. Comparison with the rate of deposition in a somewhat comparable modern environment, the Black Sea, further substantiates this time assumption. For example, if it is conservatively assumed that there has been a diagenetic reduction of the sediment thickness of about $60 \%$ (it may have been up to $80 \%$; Muller, 1967), then the original thickness of the total Kimmeridgian sequence was about $1250 \mathrm{~m}$. This works out to an average depositional rate of $25 \mathrm{~cm} / 1000$ years, a figure comparable to recent estimates of deposition in parts of the Black Sea (Ross et al., 1970). 
A final consideration is that there are so many different estimates of cyclic events (cf. Duff, et al., 1967) that it is not difficult to find one which coinçides with almost any apparent periodicity. However, in the following discussion some interesting coincidences are brought out.

\section{DISCUSSION OF RESULTS}

The single Fourier series analysis of the data of Table I is expressed graphically for each element (Fig.2) by plotting each harmonic number against its amplitude relative to all the other peaks for that element. The thickness of sediment (i.e., cycle period) represented by each harmonic number is found by simply dividing the thickness of the sequence studied $(20 \mathrm{~m})$ by the harmonic number. Thus, the first harmonic represents a cycle of $20 \mathrm{~m}$; the second, $10 \mathrm{~m}$; the fourth $5 \mathrm{~m}$, and so on. The higher the peak relative to the neigh bouring peaks, the greater the importance of the harmonic. The important features are:

(1) The high amplitude values shown by a number of elements for the first harmonic may indicate that the Blackstone sequence as a whole constitutes a cycle. The doubt lies in the fact that the first harmonic is a root mean square value and may only be indicating a cyclical trend (a segment of a cycle) rather than a complete cycle (Fig.3). It would need a broader examination of a thicker part of the sequence to ascertain whether or not this constitutes a complete cycle. If this is a cycle, then it represents a period of 200,000 years based on the above estimate that $1 \mathrm{~m}$ of sediment corresponds to 10,000 years. This is the same duration as that estimated for a model Yoredale cyclothem (Westoll, 1962).

(2) The high amplitudes for the second harmonic suggest a 10-m cycle interval corresponding to a period of 100,000 years. A possible physical explanation for this cycle is the variation in the earth's eccentricity - a period of 97,000 years (Duff et al., 1967). This phenomenon is the progressive change of the earth's orbit around the sun and could well give rise to coincident climatic fluctuations caused by changes in the degree of the sun's radiation on earth.

(3) Excluding the above two harmonics (which are of questionable validity - see previous section), the fifth is that with the highest amplitude for eight of the chemical components (organic matter, $\mathrm{V}, \mathrm{Cr}, \mathrm{Zr}, \mathrm{Mn}, \mathrm{Rb}, \mathrm{Li}, \mathrm{Sc}$ ). A further five elements $(\mathrm{Cu}, \mathrm{P}, \mathrm{Mo}, \mathrm{Ga}, \mathrm{Cs})$ have the fourth-degree harmonic as that showing either the first or second highest amplitude. Of the remaining two components $\mathrm{CO}_{2}$ has the 6 th harmonic showing the highest amplitude, leaving $\mathrm{Ni}$ as the only element not to show a dominant periodicity at about this level. The reason for this is thought to lie in the fact that two (out of the 80 ) samples yield $250 \mathrm{ppm} \mathrm{Ni}$, thereby giving the distribution for that element a strong negative skew and distorting the harmonic pattern.

Thus, fourteen out of the fifteen components reveal high amplitude harmonics between the 4 th and 6 th degrees, with the 5 th being the most impor- 

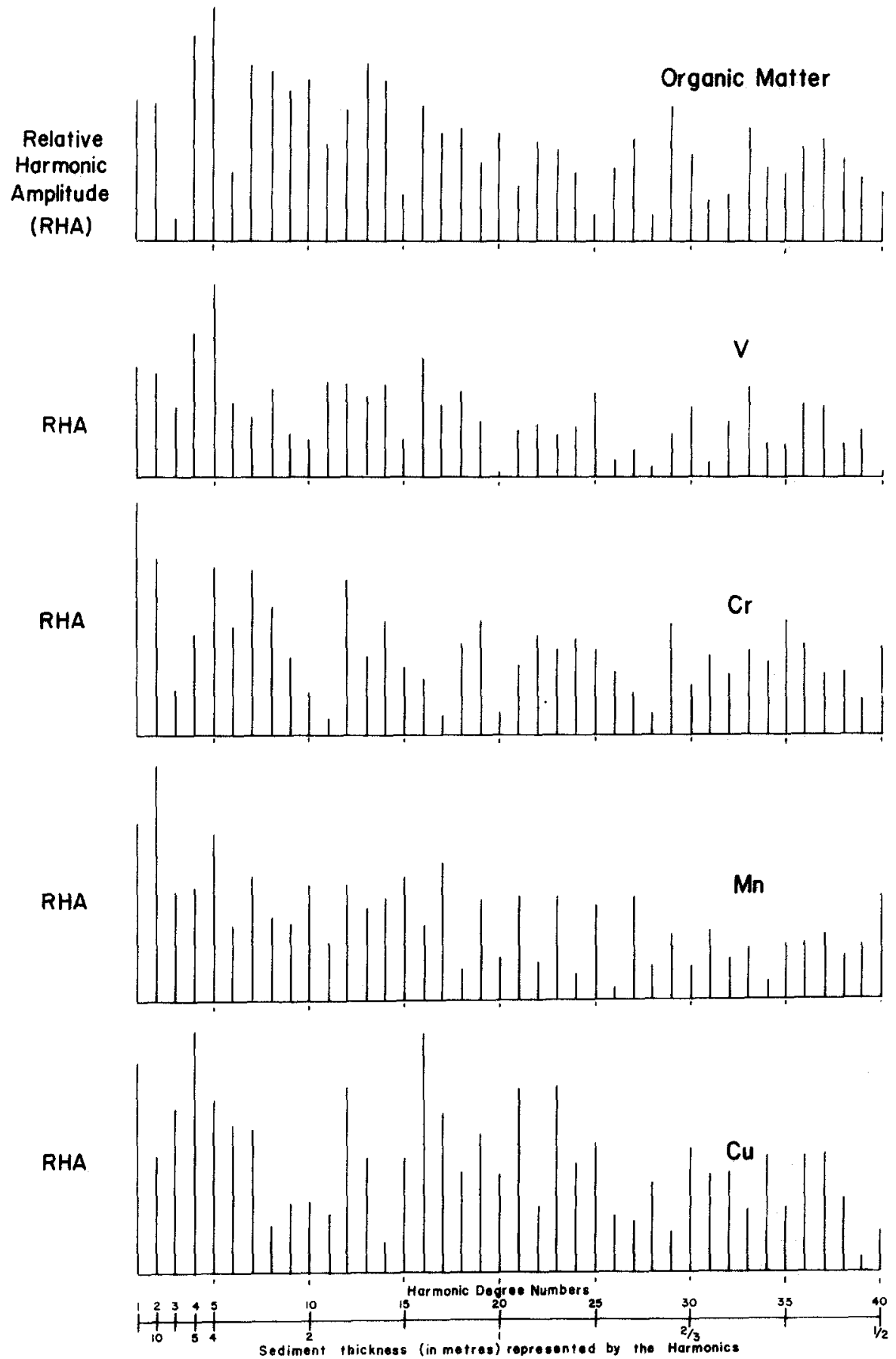

Fig. 2. Single Fourier series analysis of the geochemical data. Graphic representation of the relative harmonic amplitude (RHA) of each harmonic degree number for each chemical component. 

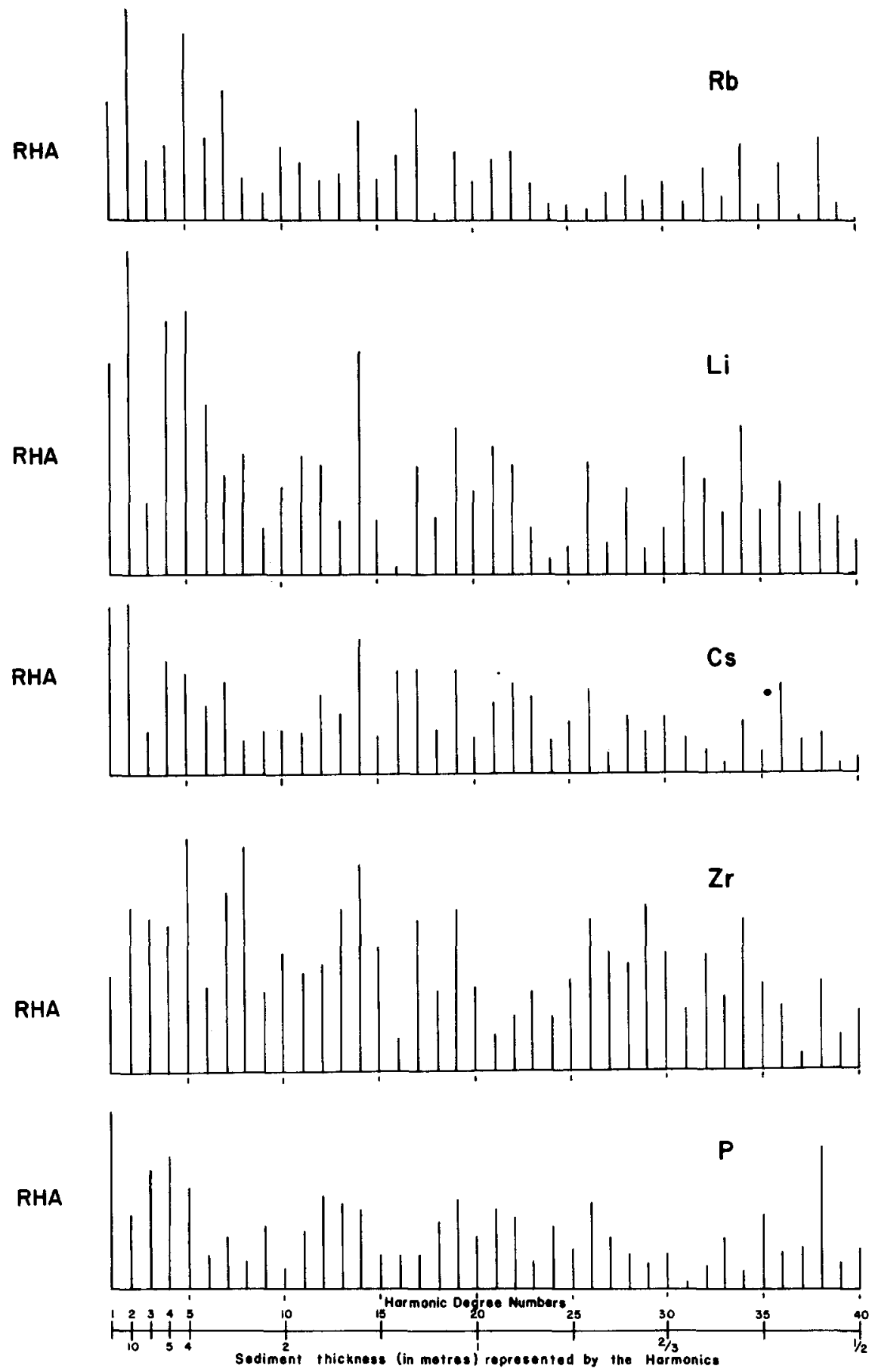

Fig.2. (legend see p. 226) 

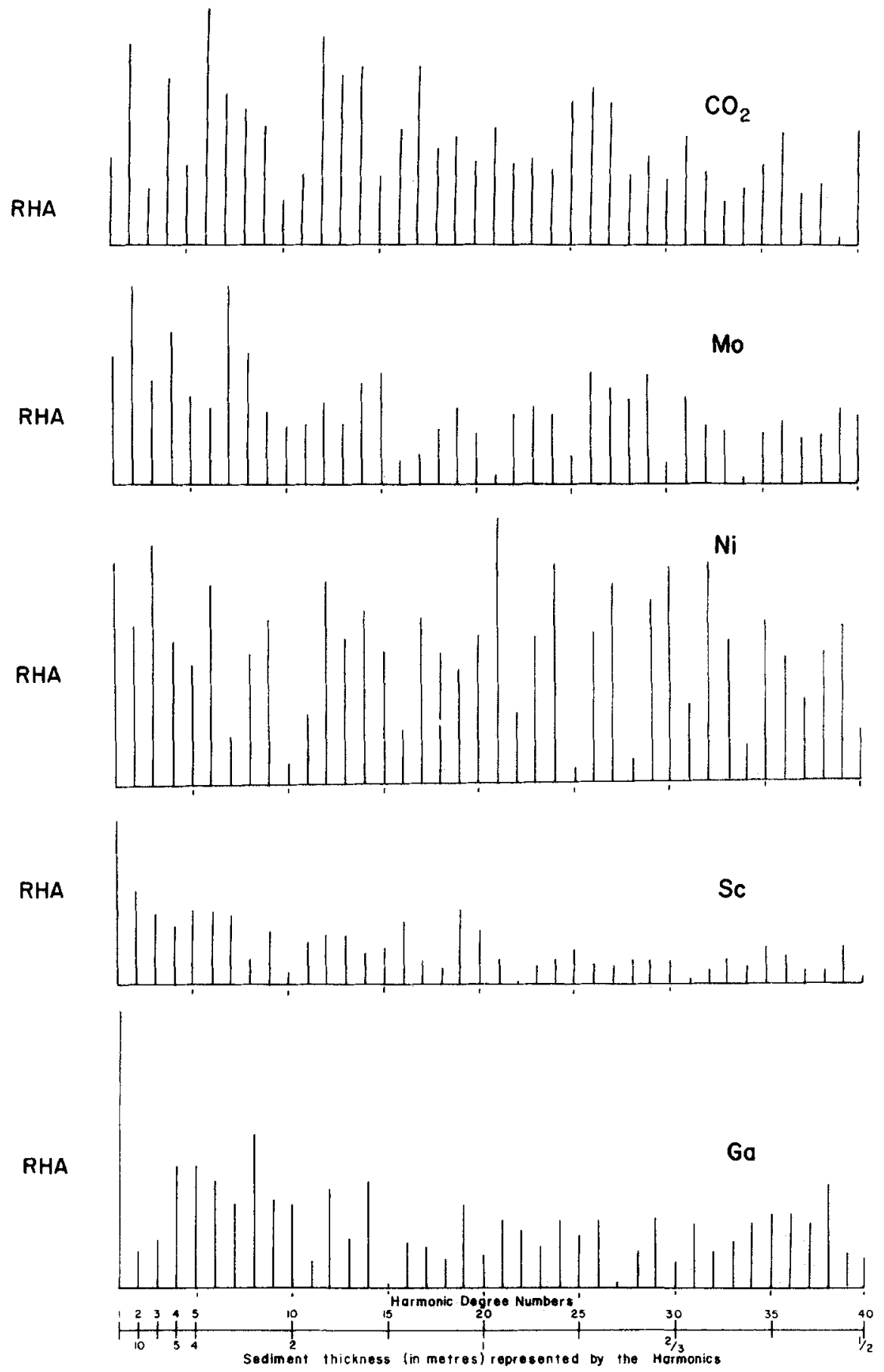

Fig. 2, (legend see p. 226). 

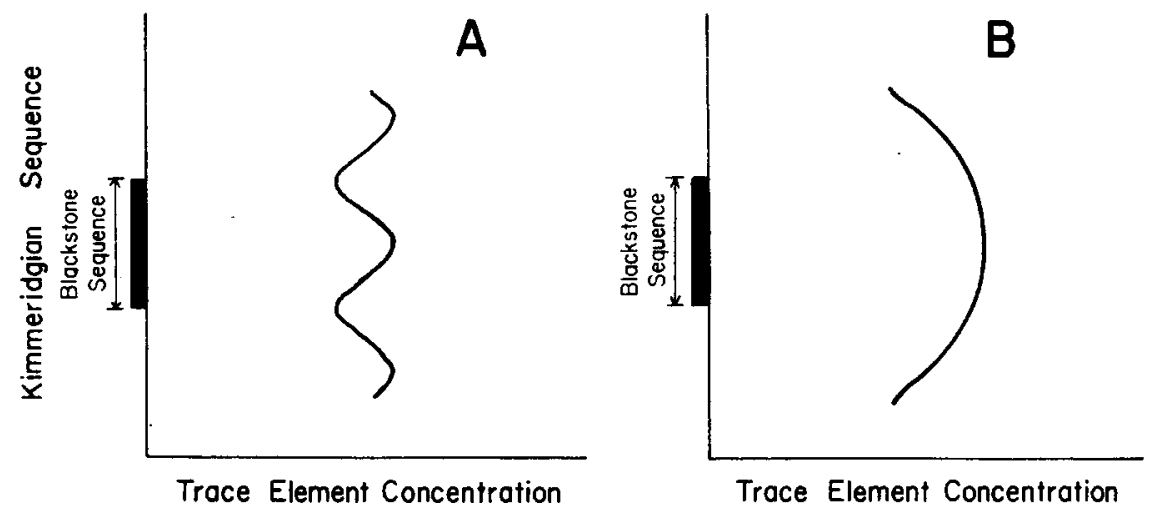

Fig. 3. A. Blackstone sequence showing a complete cycle. B. Blackstone sequence showing only a segment of a cycle, hence it indicates just a cyclic trend.

tant. The latter represents a periodicity of $4 \mathrm{~m}$, and the thickness range attributed to the 4th to 6 th harmonics is $3.3-5 \mathrm{~m}$, i.e., 33,000-50,000 years, with the dominant periodicity being in the region of 40,000 years.

It is a noteworthy coincidence that the average periodicity of the obliquity of the earth's ecliptic is also around 40,000 years. This phenomenon is a gradual change in the tilt of the earth's axis from a minimum angle of $2112^{\circ}$ to a maximum of $2412^{\circ}$ with reference to its plane of orbit around the sun. The movement is due to the perturbations which the other planets in the solar system exert on the earth's orbit (Brouwer and Van Woerkom, 1950). The effect of such movement is to gradually alter the degree of sun's radiation at any one spot on the earth's surface. As in (2) above, the result would be to modify the climate, which in turn would cause a shift in the chemical equilibrium of a basin's waters, and ultimately alter the trace-element composition of the accumulating sediment.

(4) Most of the trace elements show high amplitude values between the 12th and 15th harmonics, and particularly on the 14th. This range gives a stratigraphic interval of $1.66-1.33 \mathrm{~m}$, and $1.43 \mathrm{~m}$ for the 14th harmonic. An interesting coincidence here is that an earlier study of $205 \mathrm{~m}$ of the Kimmeridgian sediments at this locality (Downie, 1955) revealed 141 cycles with an average thickness of $1.45 \mathrm{~m}$, which is remarkably close to the geochemical cycle indicated by the Fourier analysis.

The estimated duration of just over 14,000 years has not been found to coincide with any known natural phenomenon which might be invoked as an explanation. There is the possibility that this may reflect a tectonic pulse.

(5) The 19th harmonic shows relatively high amplitude values for $\mathrm{Cr}, \mathrm{P}, \mathrm{Zr}$, $\mathrm{Mo}, \mathrm{Ga}, \mathrm{Mn}, \mathrm{Cs}, \mathrm{Li}, \mathrm{Sc}$, and perhaps $\mathrm{Cu}$ and $\mathrm{Rb}$. This suggests a periodicity of just over every $1 \mathrm{~m}$ of sediment (approx. 11,000 years), and again it is difficult to ascribe any known process as a cause. A tectonic or climatic period would be equally acceptable. Similarly, there appear to be other harmonics 
(notably the 26th and 36th) showing relatively high values which do not seem to tie in with any known periodic phenomena.

\section{SUMMARY AND CONCLUSIONS}

From the 20-m interval of the Kimmeridgian sequence studied, a simple Fourier analysis of the geochemical data has indicated several superimposed periodicities:

(a) The entire interval may represent a cycle of 200,000 years duration, although it may be just an indication of a cyclical trend, the full cycle being of longer duration.

(b) A cycle of 100,000 years could be explained by climate changes brought about by the period of variation in the earth's eccentricity.

(c) A 40,000-year cycle, which is strongly brought out by the analysis, may be attributed to climatic changes resulting from the periodicity of the obliquity of the earth's ecliptic.

(d) The 1.43-m cycle revealed by the present study is in close accord with the average cycle of $1.45 \mathrm{~m}$ observed by Downie (1955) over a much larger interval of the Kimmeridgian sequence. A duration of about 14,000 years is estimated.

(e) The latter cycle, along with several others (notably the 19th, corresponding to 11,000 years, and possibly the 26 th and 36 th) cannot be attributed to any known natural phenomena. Tectonic pulses remain a distinct possibility but are entirely conjectural, whereas astronomical evidence lends some support to the suggested climatic cycles.

Provided due consideration is given to the vagaries of Fourier analysis when interpreting results, it is concluded that the application of single Fourier series analysis to geochemical data obtained from stratigraphic sequences is a potentially useful technique for delineating cyclic trends which are difficult to define using other criteria.

\section{ACKNOWLEDGEMENTS}

This paper is based upon part of the author's doctoral dissertation prepared during the tenure of a research post at Kingston Polytechnic, England, under the supervision of Dr. R.C.L. Wilson. Grateful acknowledgement is made to Newcastle University for the use of equipment for geochemical analysis and to Reading University for the use of their computer. Dr. C. McCann kindly supplied the computer program, and Dr. G.R. Till provided much help and advice. Thanks are extended to Drs. G.R. Till, J.E. Brindle, A.C. Kendall and F. Simpson for constructive criticism of the manuscript. 


\section{REFERENCES}

Anderson, R.Y. and Koopmans, L.H., 1963. Harmonic analysis of varve time series. J. Geophys. Res., 68: 877-893.

Arkell, W.J., 1933. The Jurassic System in Great Britain. Oxford Univ. Press, London, 681 pp.

Blake, J.F., 1875. On the Kimmeridge Clay of England. Q.J. Geol. Soc. Lond., 31: 196237.

Brouwer, D. and Van Woerkom, A.J., 1950. The secular variations of the orbital elements of the principal planets. Astron. Pap. Am. Ephem., 13(2): 81.

Cope, J.C.W., 1967. The palaeontology and stratigraphy of the lower part of the Upper Kimmeridge Clay of Dorset. Bull. Brit. Mus. Nat. Hist., 15(1): 4-80.

Downie, C., 1955. The Kimmeridge Oil Shale. Thesis, Univ. of Sheffield, 229 pp. (unpublished).

Duff, P. McL.D., Hallam, A. and Walton, E.K., 1967. Developments in Sedimentology, 10. Cyclic sedimentation. Elsevier, Amsterdam, 280 pp.

Dunn, C.E., 1972. Trace Element Geochemistry of Kimmeridgian Sediments in Dorset, Northwest France, and North Spain. Thesis, Univ. of London, 410 pp. (unpublished).

Flanagan, F.J., 1969. U.S. Geological Survey standards, II. First compilation of data for the new U.S.G.S. rocks. Geochim. Cosmochim. Acta, 33: 81-120.

Granger, C.W.J. and Hatanaka, M., 1964. Spectral Analysis of Economic Time Series. Princeton Univ. Press, Princeton, N.J., 299 pp.

Hannan, E.J., 1960. Time Series Analysis. Wiley, New York, N.Y.

Harbaugh, J.W, and Merriam, D.F., 1968. Computer Applications in Stratigraphic Analysis. Wiley, New York, N.Y., 282 pp.

Harland, W.B., Gilbert Smith, A. and Wilcock, B., (Editors), 1964. The Phanerozoic timescale - a symposium. Q.J. Geol. Soc. Lond., 120S: pp. 458.

Hudson, R.G.S., 1924. On the rhythmic succession of the Yoredale Series in Wensleydale. Proc. Yorkshire Geol. Soc., 20: 125-135.

Jenkins, G.M. and Priestley, M.B., 1957. The spectral analysis of time series. J.R. Stat. Soc. (B), 19: 1-12.

Jenkins, G.M. and Watts, D.G., 1968. Spectral Analysis and its Applications. Holden-Day, San Francisco, Calif., 525 pp.

Johnson, G.A.L., 1959. The Carboniferous stratigraphy of the Roman Wall district in western Northumberland. Proc. Yorkshire Geol. Soc., 32: 83-130.

Kvalheim, A., 1947. Spectrochemical determination of the major constituents of minerals and rocks. J. Opt. Soc. Am., 37: 585.

Lanczos, C., 1957. Applied Analysis. Pitman, London, 539 pp.

Lanczos, C., 1966. Discourse on Fourier Series. Oliver and Boyd, Edinburgh and London, $255 \mathrm{pp}$.

Miller, R.L., and Kahn, J.S., 1962. Statistical Analysis in the Geological Sciences. Wiley, New York, N.Y., $483 \mathrm{pp}$.

Moore, R.C., 1949. Divisions of the Pennsylvanian System in Kansas. Kans. Geol. Surv. Bull., 83: 203 pp.

Moore, R.C., 1959. Geological understanding of the cyclic sedimentation represented by Pennsylvanian and Permian rocks of northern Mid-Continent region. In: R.C. Moore and D.F. Merriam, (Editors), Kansas Field Conference, Guidebook for Association American State Geologists. Kansas Geol. Surv., Lawrence, Kans. pp. 46-55.

Muller, G., 1967. Diagenesis in argillaceous sediments. In: G. Larsen and G.V. Chilingar (Editors), 1967, Developments in Sedimentology, 8. Diagenesis in Sediments. Elsevier, Amsterdam, 551 pp.

Otnes, R.K. and Enochson, L., 1972. Digital Time Series Analysis. Wiley, New York, N.Y., $467 \mathrm{pp}$. 
Preston, F.W. and Harbaugh, J.W., 1965. BALGOL programs and geologic application for single and double Fourier series using IBM 7090/7094 computers. Kans. Geol. Surv., Spec. Distr. Publ., 24: 72 pp.

Preston, F.W. and Henderson, J.H., 1964. Fourier series characterization of cyclic sediments for stratigraphic correlation. Kans. Geol. Surv. Bull., 169(2): 415-425.

Ross, D.A., Degens, E.T. and MacIlvaine, J., 1970. Black Sea: Recent sedimentary history. Science, 170: 163-165.

Stanton, R.E., 1966. Rapid Methods of Trace Analysis (For Geochemical Applications). Arnold, London, $96 \mathrm{pp}$.

Westoll, T.S., 1962. The standard model cyclothem of the Visean and Namurian sequence of northern England. Congr. Avan. Etudes Stratigraph. Geol. Carbonifere, C. R., 4, Heerlen, 1958, 3: 767-773.

Wylie, C.R.Jr., 1960. Advanced Engineering Mathematics. McGraw-Hill, New York, N.Y., 640 pp. 